\title{
Cloning of porcine signal transducer and activator of transcription 3 cDNA and its expression in reproductive tissues
}

\author{
Lihua Wen, Jesse Craig ${ }^{1}$, Paul W Dyce ${ }^{1}$ and Julang Li \\ Department of Animal and Poultry Science, University of Guelph, Guelph, Ontario, Canada and ${ }^{1}$ Reproductive \\ Biology Unit and Division of Reproductive Medicine, Department of Obstetrics and Gynecology and Cellular and \\ Molecular Medicine, University of Ottawa, Hormones, Growth and Development, Program, Ottawa Health Research \\ Institute, Ottawa, Ontario, Canada K1Y 4E9
}

Correspondence should be addressed to J Li; Email: jli@uoguelph.ca

\begin{abstract}
The signal transducer and activator of transcription 3 (Stat3) protein is a member of the Stat family that has a variety of biological functions including cell growth, anti-apoptosis, and cell motility, depending on the cell type and stimulus. Recent studies have suggested that Stat 3 plays an important role in embryo development. Although the Stat 3 gene has been cloned in humans, mice, cow, and rats, its sequence in pigs is unknown. In the present study, the 2476 bp Stat 3 cDNA was cloned using real time reverse transcriptase (RT)-PCR. Comparison of sequences across species revealed that the porcine Stat3 cDNA is 93 and $90 \%$ homologous to human and mouse respectively. To study the expression pattern of Stat3, RNA and protein were isolated from heart, lung, kidney, ovary, oviduct, and uterus tissues. RT-PCR and western blot indicated that Stat3 is expressed in all the tissues tested, and the level of expression is relatively high in tissues from the reproductive system. In addition, immunohistochemistry studies suggested that the Stat3 protein was present in the oocyte, granulosa, theca, and interstitial cells of the ovary, the mucosal folds in the oviduct, and both the epithelium and stromal layers in the endometrium. To study whether Stat3 is functional in responding to growth factor stimulation in the ovary, granulosa cells were isolated from large follicles $(>3 \mathrm{~mm})$ and cultured in the presence of epidermal growth factor (EGF; $10 \mathrm{ng} / \mathrm{ml}$ ) for 5, 10, 15, 30, and $60 \mathrm{~min}$, following which western blots were performed using an antibody against the phosphorylated Stat3. Phosphorylated Stat 3 was upregulated following 5 min of EGF challenge and was sustained during the 15-min stimulation, and decreased back to the control level following 60-min stimulation. The translocation of phosphorylated Stat3 from cytoplasm to nucleus following stimulation of EGF was also detected via immunocytochemistry. Our data suggests that Stat3 may play a role in porcine ovarian function.

Reproduction (2006) 132 511-518
\end{abstract}

\section{Introduction}

The signal transducer and activator of transcription (Stat) proteins are latent cytoplasmic transcription factors that are activated by a series of extracellular signaling proteins, such as cytokines, growth factors, and hormones (Zhong et al. 1994, Ihle 1995, Shimoda et al. 1997). Seven members of the Stat family (Stat1, $2,3,4,5 \mathrm{~A}, 5 \mathrm{~B}$ and 6 ) have been identified in mammals. Each has varying functions and all are important for mediating cellular signaling (for reviews see Darnell 1997, Aaronson \& Horvath 2002).

Signal transducer and activator of transcription 3 (Stat3) was originally identified as an interleukin-6 (IL-6) responsive acute-phase factor in the mouse liver, which was capable of selectively interacting with an enhancer element in the promoter sequence of acute-phase genes
(Raz et al. 1994, Akira 2000). Similar to other Stat proteins, Stat3 is activated by tyrosine phosphorylation at a single site (Y705) close to the carboxyl terminus, and by serine phosphorylation at a site within the C-terminal transactivation domain (S727). Binding of the IL-6 family cytokines to their specific receptors leads to the heterodimerization of gp130 with cytokine-specific receptors, resulting in the activation of the Janus kinase (JAK) pathway. Subsequently, gp130 is phosphorylated on tyrosine $767,814,905$, and 915, providing docking sites for the Stat3 Src homology $2(\mathrm{SH} 2)$ domain. Stat3 is then phosphorylated by JAK, which is required for its dimerization, nuclear translocation and transcriptional activity (Greenlund et al. 1995, Guschin et al. 1995).

Stat3 plays a crucial role in a variety of biological functions including cell growth, survival, and motility 
depending on the cell type and stimulus (for review, see Akira 1999). Stat3 is essential during embryogenesis, given that disruption of the mouse Stat3 gene is embryonic lethal at approximately E6.5-7.5 (Takeda et al. 1997). Stat3 also plays an important role in mouse and rat reproduction during implantation and decidualization (Teng et al. 2004a, 2004b). Additionally, it has recently been reported that leptin regulates porcine ovarian granulosa cell function via the JAK/STAT pathway (Ruiz-Cortes 2003). In addition to IL-6, Stat3 is also activated by other factors, such as the leukemia inhibitory factor (Stewart et al. 1992), epidermal growth factor (EGF; Threadgill et al. 1995, Chan et al. 2004), colony-stimulation factor-1 (Yoshida et al. 1990, Stahl et al. 1995), and leptin (Takeda et al. 1997).

The Stat 3 gene has been cloned in humans (Akira et al. 1994), mice (Zhong et al. 1994), and rats (Ripperger et al. 1995), but not in the pigs. EGF is known to stimulate ovarian follicular development in pigs (Mao et al. 2004), cows (Gutierrez et al. 2000) and rats (Romano et al. 1994). It was reported that its action on ovarian granulosa cells occurs via the MAP kinase pathway (Keel et al. 1995, Keel \& Davis 1999). Whether the Stat3 pathway is also involved in mediating EGF regulation of ovarian function remains unknown. The objective of the present study was to clone the porcine Stat3 coding sequence, study its expression distribution pattern in porcine tissues, and its possible involvement in EGF signaling in porcine granulosa cells.

\section{Materials and Methods \\ cDNA cloning and sequencing}

We have previously reported the expression of Stat 3 in porcine skin stem cells (Dyce et al. 2004). In the present study, total RNA was isolated from porcine skin stem cells, and reverse transcribed and amplified by PCR using a long template PCR system (Boehringer Mannheim $\mathrm{GmbH}$, Germany) according to the manufacturer's instructions. The primers used in the PCR amplification were: forward $5^{\prime}$-acaggatccttgacgagcac- $3^{\prime}$ and reverse $5^{\prime}$-ctctctgcagctcctgtcct- $3^{\prime}$, based on porcine expressed sequence tags (ESTs) (GenBank accession no. CK453710 and BX675510), which are highly homologous (94 and 93\% respectively) with human Stat 3 mRNA (NM_139276). PCR was performed using Platinum's Taq DNA polymerase (Invitrogen). The PCR product was cleaned and ligated to the pGEM-T Easy vector (Promega). The resulting plasmids with Stat3 cDNA from four independent PCR were sequenced to confirm their identity.

\section{Sample collection}

Tissues (lung, kidney, heart, ovary, oviduct, and uterus) were collected from five Yorkshire gilts at slaughter from an abattoir and frozen immediately using liquid nitrogen. Once frozen, tissues were stored at $-80^{\circ} \mathrm{C}$ until analysis.

\section{RNA isolation and real time RT-PCR}

Total RNA was isolated using Trizol reagent (Invitrogen). Approximately, $0.5 \mu \mathrm{g}$ RNA was DNase I treated and reverse transcriptase (RT)-PCR was performed according to the manufacturer's directions (Invitrogen). Real Time RT-PCR was performed using the SYBR Green PCR kit (Qiagen) and a Smart Cycler thermocycler (Cepheid, Sunnyvale, CA, USA). Briefly, $12.5 \mu \mathrm{l}$ SYBR Green $2 \times$ mix (contains HotStar Taq DNA polymerase, QuantiTect SYPR Green PCR buffer, dNTP mix, SYBR Green 1, and $5 \mathrm{mMMgCl}_{2}$ ), $0.3 \mu \mathrm{M}$ each of primer (Dyce et al. 2004; 5'cccgtacctgaagaccaagt- $3^{\prime}$ and $5^{\prime}$-ggttcagcagcttcaccatt-3') and $2.5 \mu \mathrm{l} \mathrm{cDNA}$ were included in a $25 \mu \mathrm{l}$ PCR. Melt curve analysis was performed to confirm the specificity of the products amplified. The relative expression was analyzed using $2^{-\Delta \Delta C t}$ method (Livak \& Schmittgen 2001). Hypoxanthine-phosphoribosyltransferase (HPRT) was used as a housekeeping control using primers: $5^{\prime}$-ccagtcaacgggcgatataa- $3^{\prime}$ and $5^{\prime}$-cttgaccaaggaaagcaagg- $3^{\prime}$. All PCR products were sequenced to confirm their identity.

\section{Protein isolation and western blot analysis}

Protein was isolated using a previously described method (Matsuoka et al. 1999). Approximately, $0.5 \mathrm{~g}$ of each tissue was homogenized in $1 \mathrm{ml}$ ice-cold buffer using a homogenizer. Protein was quantified using Bio-Rad protein quantification reagent, and approximately $30 \mu \mathrm{g}$ protein was subjected to $10 \%$ SDS-PAGE. Protein was transferred to a PVDF membrane (Millipore), which was blocked overnight in $5 \%$ skim milk at $4{ }^{\circ} \mathrm{C}$. The membranes were incubated with antibody against Stat3 (1:1000, rabbit antihuman, Santa Cruz Biotechnology), glyceraldehyde-3phosphate dehydrogenase (GAPDH) (1:40 000, rabbit anti-human, Santa Cruz Biotechnology) and phosphorylated Stat3 (1:1000, p-Stat3 Y705, rabbit anti-human, Santa Cruz Biotechnology) respectively, diluted in PBS, $0.1 \%$ Tween-20 and 5\% skim milk powder for $1 \mathrm{~h}$ at room temperature, and followed by incubation with the secondary antibody $(1: 8000$, goat anti-rabbit IgG horseradish peroxidase; Cell Signaling Technology) for $1 \mathrm{~h}$ at room temperature. Proteins were detected using the $\mathrm{ECL}$ Advance Western Blotting Detection Kit (Amersham). Digital images of X-ray films were obtained using GeneSnap and densitometry of band intensities was performed using GeneTools (Syngene).

\section{Granulosa cell isolation, culture and epidermal growth factor stimulation}

Porcine ovaries (approximately 70 ovaries were used per experiment) were collected from pre-pubertal gilts 
at a local slaughterhouse and transported to the laboratory in PBS $\left(37^{\circ} \mathrm{C}\right)$. Granulosa cells were aspirated from large-sized $(>3 \mathrm{~mm})$ follicles, pelleted, and cultured as previously described (Li et al. 1995). Briefly, viable cells $\left(7-9 \times 10^{6}\right.$ cells $\left./ \mathrm{ml}\right)$ in minimum essential medium (Gibco BRL) containing $1 \mathrm{mg} / \mathrm{l}$ insulin (Sigma), $0.1 \mathrm{mM}$ non-essential amino acids (Gibco BRL), $5 \times 10^{4} \mathrm{IU} / \mathrm{I}$ penicillin (Gibco BRL), $50 \mathrm{mg} / \mathrm{l}$ streptomycin (Gibco BRL), $0.5 \mathrm{mg} / \mathrm{l}$ fungizone (Gibco $B R L$ ), and $10 \%$ fetal calf serum (FCS; Gibco BRL) were plated in $2 \mathrm{ml}$ on a $3.5 \mathrm{~cm}$ cell culture dish (Corning) for $24 \mathrm{~h}$ at $37^{\circ} \mathrm{C}$. EGF $(10 \mathrm{ng} / \mathrm{ml})$ challenges were performed at the time of $0,5,10,15,30$, and $60 \mathrm{~min}$, and cells were immediately lysed for western blot analysis or fixed for immunocytochemistry.

\section{Immunofluorescence}

For tissue sections: tissues were fixed with $10 \%$ formalin for 20-24 $\mathrm{h}$ and paraffin-embedded. Tissue sections of $5 \mu \mathrm{m}$ were deparafinized in Xylene (Fisher) and rehydrated in decreasing concentrations of ethanol (100, 90, and $70 \%$ ). Following $0.2 \%$ sodium borohydride treatment, a non-specific binding was blocked by incubation in 5\% non-immune rabbit serum (Invitrogen). Slides were incubated overnight at $4{ }^{\circ} \mathrm{C}$ in a humidified chamber with the primary antibody $(1: 300$, rabbit anti-human Stat3, Santa Cruz Biotechnology). After two washes in PBS, the secondary antibody (1:500, goat anti-rabbit IgG FITC, fluorescein isothiocyanate, Sigma) was incubated with the slides for $2 \mathrm{~h}$ in the dark. Slides were counter stained with 4,6diamidino-2-phenylindole (DAPI), and coverslips were mounted using fluorescent mounting medium (DakoCytomation). Negative control slides were subjected to the same method, in which the first antibodies were substituted with an equivalent dilution of non-immune rabbit serum (Invitrogen). Fluorescence was detected using an Olympus BX-UCB microscope and MetaMorph image analysis software (Universal Imaging Corporation).

For cultured cells: granulosa cells were fixed in $4 \%$ paraformaldehyde for $20 \mathrm{~min}$ followed by treatment in $0.1 \%$ Tween 20 for $10 \mathrm{~min}$. Cells were then blocked and permeabilized in PBS supplemented with $0.1 \%$ Triton X-100 and 5\% BSA for $1 \mathrm{~h}$. Rabbit anti-human Stat3 (1:500) or p-Stat3 (1:500, Santa Cruz Biotechnology) was incubated with the blocked cells for $2 \mathrm{~h}$, followed by goat anti-rabbit FITC secondary antibody incubation (1:1000, Sigma) for $1.5 \mathrm{~h}$ at room temperature. Cells were counterstained with DAPI, and mounted on slides with fluorescent mounting medium. For negative controls, slides were subjected to the same method, except the primary antibodies were substituted with equivalent dilution of non-immune rabbit serum (Invitrogen). Fluorescence was examined using an Olympus BX-UCB microscope and MetaMorph image analysis software (Universal Imaging Corporation). The percentage of nuclei $p$-Stat3 positive cells ( $p$-Stat3 positive nuclei/total $\mathrm{p}$-Stat3 positive cells) was determined by counting at least 150 p-Stat3 positive cells per group.

\section{Statistical analysis}

Relative levels of Stat 3 mRNA and protein, and p-Stat3 proteins were analyzed by ANOVA. Significant results were analyzed by Tukey's multiple comparison test. Results were considered significant at $P<0.05$. Each experiment was repeated at least three times.

\section{Results \\ Cloning and sequencing of porcine Stat 3 cDNA}

Porcine ESTs homologous with human Stat3 mRNA sequence were obtained using NCBI's Blastn database search. ESTs CK453710 and BX675510 were 94 and $93 \%$ homologous to the human $5^{\prime}$ and $3^{\prime}$ Stat 3 mRNA sequence including the translational start and stop codon respectively. Primers were designed based on these ESTs and used to obtain a 2476 bp porcine Stat 3 coding sequence (DQ470570, Fig. 1a) via RT-PCR. The porcine sequence was compared to the human (NM_139276) and the mouse (NM_213659) Stat3 cDNA sequences using NCBI's Align Two Sequences Tool. Overall, the porcine cDNA sequence shows 93 and $90 \%$ homology to human and mouse mRNA sequences respectively. Individual functional domain encoding sequences show variable homology, ranging from 89 to $96 \%$. As shown in Fig. $1 \mathrm{~b}$, the $\mathrm{N}$-terminal domain encoding sequence is 93 and $92 \%$ homologous to human and mouse respectively. The DNA binding domain-encoding sequence is 92 and $90 \%$ homologous to human and mouse respectively. The $\mathrm{SH} 2$ domain-encoding sequence is 94 and $89 \%$ homologous to human and mouse respectively, while the C-terminal domain is 96 and $94 \%$ homologous respectively. The predicted pig Stat3 amino acid sequence is highly homologous (>99\%) with human and mouse Stat3 protein.

\section{Stat3 mRNA expression in porcine tissues}

To study the expression pattern of Stat 3 mRNA, total RNA was isolated from porcine heart, lung, kidney, and female reproductive tissues (ovary, oviduct, and uterus). The relative levels of Stat 3 mRNA were determined using Real Time RT-PCR. As shown in Fig. 2, the 129 bp Stat3 PCR products were detectable in all the tissues tested. Quantitation using the $2^{-\Delta \Delta C t}$ method (Livak \& Schmittgen 2001) suggested that the expression is higher in the reproductive organs and lung, when compared to that in the heart and kidney. 


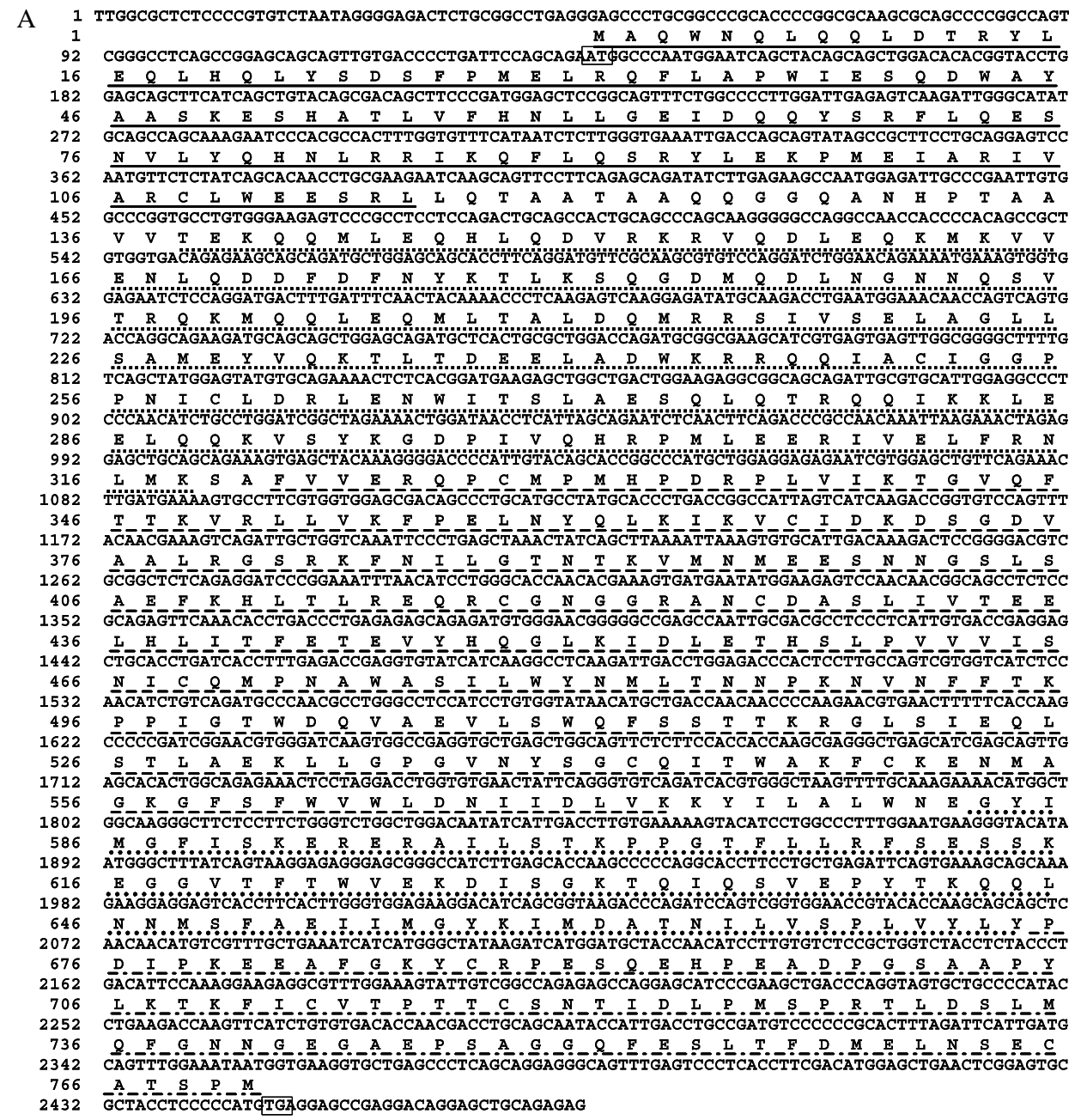

B

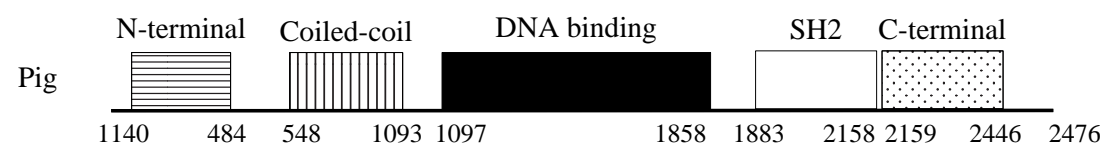

Human: $93 \%$ overall homology

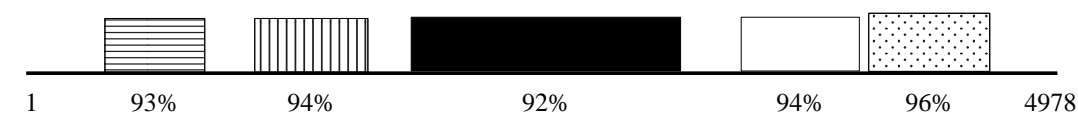

Mouse: $90 \%$ overall homology

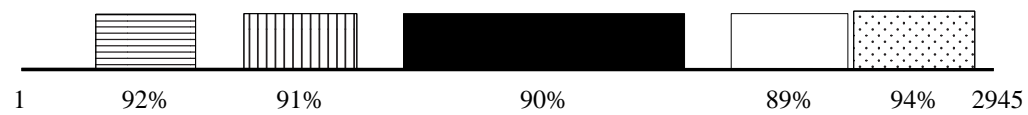

Figure 1 (a) Porcine Stat3 cDNA sequence (DQ470570) and predicted amino acid sequence. Both the start and stop codons are shown in boxes. The conserved domains are underlined: solid, N-terminal domain; square dot, coiled-coil domain; long dash, DNA-binding domain; round dot, $\mathrm{SH} 2$ domain; and dash dot, C-terminal domain. (b) Comparison of Stat3 sequences encoding functional domains from the pig, human, and mouse. The porcine Stat3 cDNA sequence was compared with that of human (NM_139276) and mouse (NM_213659) sequences using NCBI's blastn program. The functional domains of the predicted Stat3 are shown in bars: horizontal, N-terminal domain; vertical, coiled-coil domain; solid, DNA-binding domain; open, SH2 domain; and dot, C-terminal domain. The sequence was from four independent reverse transcriptase (RT)-PCRs.

\section{Stat3 protein expression and localization}

Consistent with the mRNA study, Stat3 protein was detected in all tissues analyzed (Fig. 3a), however, the relative expression level in the kidney and heart was significantly lower $(P<0.05)$ than in the other tissues tested (Fig. 3b).

To further study where Stat 3 is present and may exert its physiological role within the reproductive tissues, 


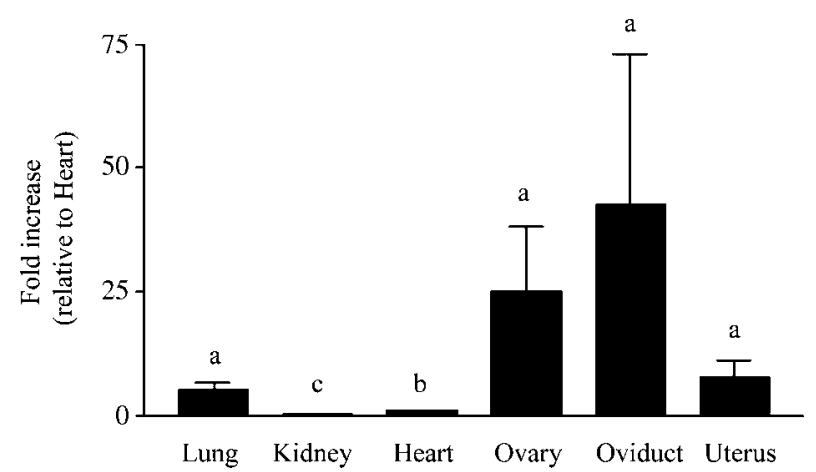

Figure 2 Detection of Stat3 mRNA in adult pig tissues. Total RNA was isolated from porcine tissues and reverse transcribed to cDNA. Ten percent of the RT reaction was used as a template for real time RT-PCR amplification of Stat3 and HPRT. Expression of HPRT was used for normalization of $\mathrm{Ct}$ values, and the $2^{-\Delta \Delta \mathrm{Ct}}$ methods were used to calculate the relative expression between tissues. Relative levels of Stat3 mRNA are shown in this figure. Data are the mean \pm s.E.M. of four independent experiments using four animals. Different alphabetical letters indicate statistical differences $(P<0.05)$.

immunofluorescence was performed on paraffin embedded porcine ovarian, oviduct, uterine tissues, and cultured granulosa cells. In the ovary, Stat3 was localized in the oocyte, granulosa, theca, and interstitial cells, with a similar localization pattern from preantral and antral follicles (Fig. 4a, g), while in the oviduct Stat3 was detected primarily in the mucosal folds (Fig. 4c).

A

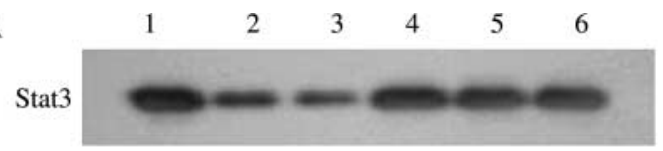

$92 \mathrm{kD}$

GAPDH

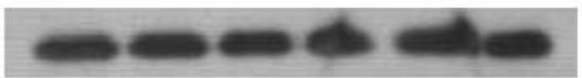

$37 \mathrm{kD}$

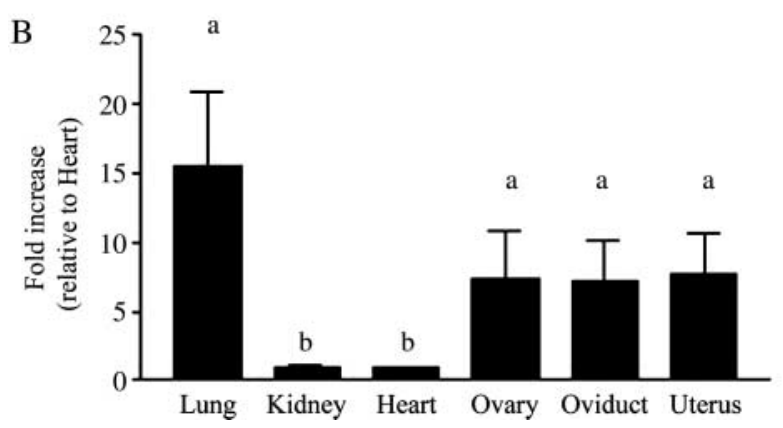

Figure 3 Protein expression of Stat 3 in porcine tissues. Protein was isolated from gilts tissues and subjected to SDS-PAGE. (a) Representative western blot of Stat3 and GAPDH. Lane 1, lung; lane 2, kidney; lane 3, heart; lane 4, ovary; lane 5, oviduct; and lane 6, uterus. (b) Relative levels of Stat3 expression. Data are expressed as the fold of heart Stat 3 expression and are the mean \pm S.E.M. of five independent experiments using five animals. Different alphabetical letters indicate a statistical difference $(P<0.05)$.
In the uterus, high levels of expression were observed in the endometrium both in the epithelium and stromal layers (Fig. 4e).

\section{EGF induced Stat3 phosphorylation, translocation in granulosa cells}

Since Stat3 is expressed in ovarian granulosa cells (Fig. 4a, g), we then studied whether Stat3 is phosphorylated in response to growth factor stimulation. Granulosa cells were isolated from porcine ovaries cultured in medium with $10 \%$ FCS, and challenged with EGF $(10 \mathrm{ng} / \mathrm{ml})$ for 0 (control), 5, 10, 15, 30, and $60 \mathrm{~min}$ following $24 \mathrm{~h}$ of culture. Protein was then isolated from these granulosa cells and western blots were performed to assess the content of the phosphorylated form of Stat3. As shown in Fig. 5a, although the Stat 3 protein was present in all the groups tested at a similar level, the p-Stat3 was upregulated following $5 \mathrm{~min}$ of EGF stimulation and remained high during $15 \mathrm{~min}$ of the challenge. The amount of p-Stat3 decreased following 30 min of EGF stimulation and was in at a very low level when compared to $0 \mathrm{~min}$ following 60 min of EGF stimulation. To study whether p-Stat3 is also translocated to the nucleus after phosphorylation, immunocytochemistry was performed using specific antibody against the p-Stat3. p-Stat3 was not detectable in granulosa cell nuclei prior to stimulation. From $5 \mathrm{~min}$ of EGF stimulation, p-Stat3 was observed to be present in the nuclei of some granulosa cells (Fig. $6 \mathrm{~d}, \mathrm{f}, \mathrm{h}$ ). The percentage of nuclear p-Stat3 positive cells was approximately 16,35 , and $38 \%$ for 5,10 , and 15 min respectively.

\section{Discussion}

The present study cloned the porcine Stat3 coding sequence and demonstrated that Stat 3 is expressed in various pig tissues, with relatively high levels in reproductive tissues, and can be phosphorylated in response to EGF stimulation in ovarian granulosa cells.

Comparison of human (Akira et al. 1994), mouse (Zhong et al. 1994), and rat (Ripperger et al. 1995) Stat3 coding sequences revealed that the homology between human and mouse is $90 \%$ and between human and rat is $90 \%$. Our present study shows that porcine Stat3 cDNA is 93 and $90 \%$ homologous to human and mouse Stat3 mRNA sequences respectively. This finding confirms that there is high homology over the region of coding sequence among mammalian species. Stat 3 has several conserved domains that are critical for function. This includes a N-terminal domain, coiledcoil domain, DNA-binding domain, $\mathrm{SH} 2$ domain, and C-terminal transactivation domain. The N-terminal domain allows Stat3 dimerization and is highly conserved within the Stat family (Calo et al. 2003). The Stat3 DNA-binding domain is responsible for 
A

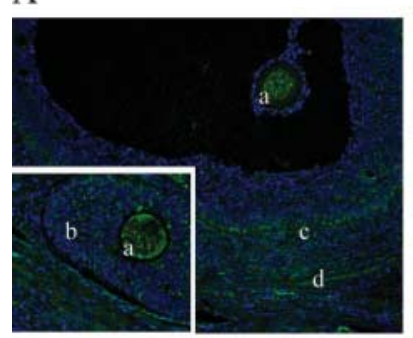

B

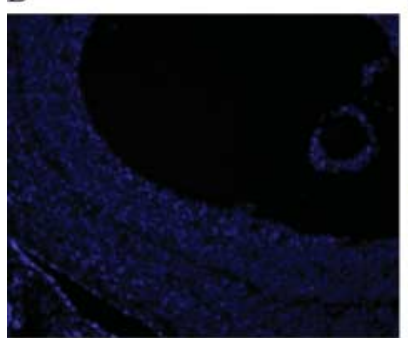

C

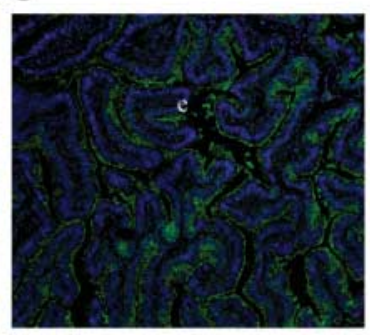

D

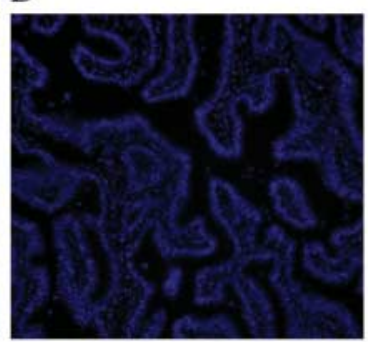

E

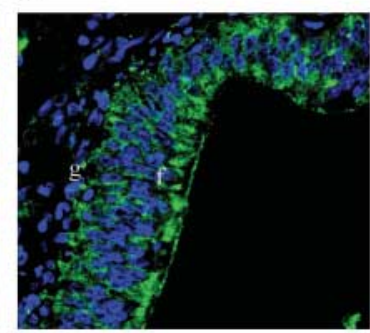

F

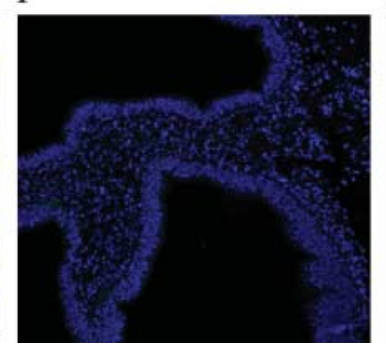

G

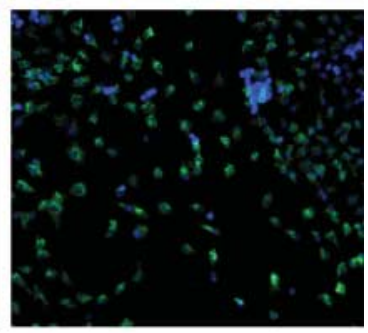

$\mathrm{H}$

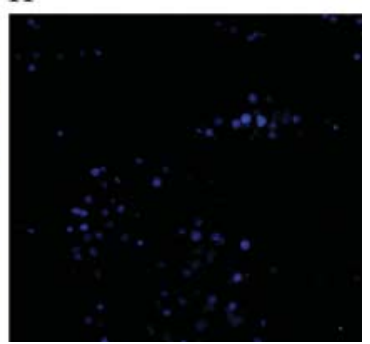

Figure 4 Localization of Stat3 protein in reproductive tissues and granulosa cells. Stat3 protein was detected (green) in porcine ovarian (A), oviduct (C), uterine (E) tissues, and isolated granulosa cells $(G)$. In the ovary, Stat3 was noted in the oocyte (a), granulosa cells (b), theca cells (c) and interstitial cells (d) in an antral follicle. A similar expression pattern was observed in a preantral follicle (Fig. a, inlet). In the oviduct Stat3 was detected in the mucosal folds (e). In the uterus, high levels of expression were noted in the endometrium, in both the epithelium (f) and stromal (g) layers. $\mathrm{B}, \mathrm{D}, \mathrm{F}$ and $\mathrm{H}$ are negative controls for ovary, oviduct, uterus and granulosa cells respectively, in which primary antibody was substituted with non-immune rabbit serum. Magnification: $A$ and insert box, C, B, D, F, G, H $100 \times$; E, $200 \times$.

binding of Stat3 to target gene sequences, which is usually a conserved DNA sequence TT $(\mathrm{N})_{4} \mathrm{AA}$ (Seidel et al. 1995). Both the coiled-coil domain and the $\mathrm{SH} 2$ domain are involved in protein-protein interactions. The $\mathrm{SH} 2$ domain is required for the recruitment of Stats to phosphorylated receptors and the $\mathrm{SH}$-phosphotyrosine interactions between monomeric Stats to form dimers (Shuai 1999). The function of the C-terminal domain is to communicate with the transcriptional complex, which has a conserved serine (Calo et al. 2003). The high homology among pig, human, and mouse Stat 3 sequences coding for functional domains suggests that the function(s) of these domains may also be conserved among mammalian species.

Stat3 plays an important role in the regulation of cell proliferation, apoptosis and cell migration in a cell specific manner (Akira 1999). Our data showed that Stat3 is expressed, both at the mRNA and protein level, in various tissues in the pig. Our findings that Stat 3 is expressed at high levels in the reproductive tissues suggest that Stat 3 may play a role in the regulation of reproductive function. The presence of Stat 3 protein in the mucosal folds of the oviduct, and the endometrium of the uterus is consistent with the previously reported role of Stat3 during early embryogenesis (Takeda et al. 1997), implantation and development (Teng et al. $2004 a, 2004 b$ ). It is possible that the expression of Stat3 in the oviduct and uterus is involved in upregulating the expression of genes that are important for early embryo development and implantation. In addition, we have also observed that Stat3 is expressed in oocytes,
A $\begin{gathered}\text { Duration of EGF } \\ \text { stimulation }(\min ) 0\end{gathered}$

stimulation (min) $0 \quad 5 \quad 10 \quad 15 \quad 30 \quad 60$

p-Stat3

Stat3
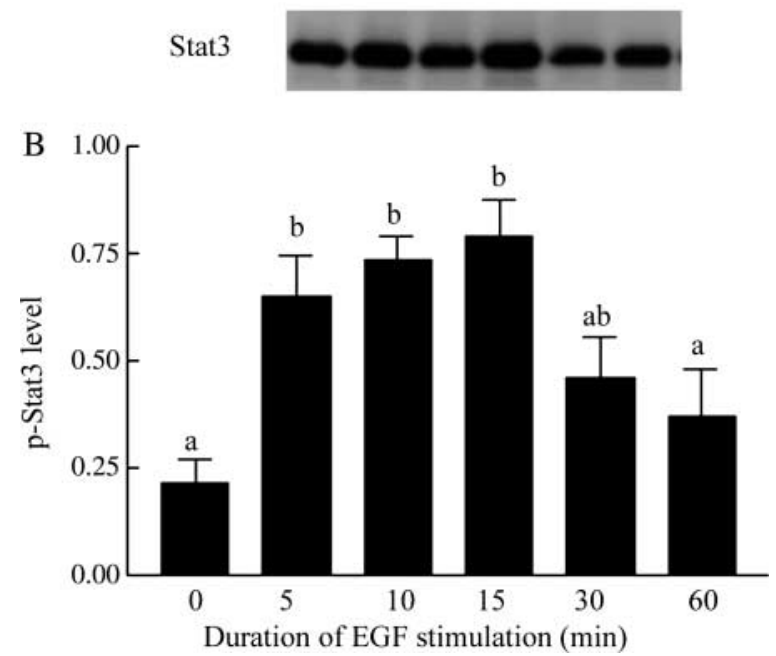

Figure 5 The phosphorylation of Stat 3 in granulosa cells in response to EGF stimulation. Granulosa cells were challenged with EGF $(10 \mathrm{ng} / \mathrm{ml})$ for 0 (control), 5, 10, 15, 30, and 60 min respectively, in the presence of $10 \%$ FCS. Protein was then isolated and western blot was performed. (a) Representative western blot of phosphorylated and non-phosphorylated Stat3. (b) Relative level by densitometry quantitation of the phosphorylated Stat3 normalized by the non-phosphorylated Stat3.

Data are the mean \pm s.E.M. of four independent experiments. Different alphabetical letters indicate a statistical difference $(P<0.05)$. 
A

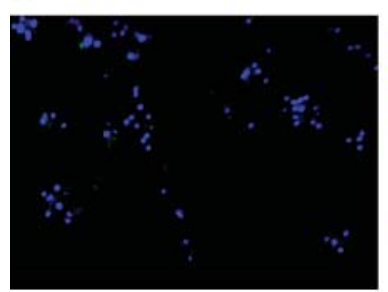

B

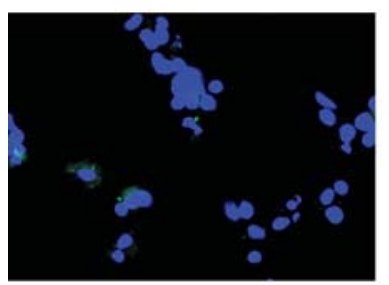

C

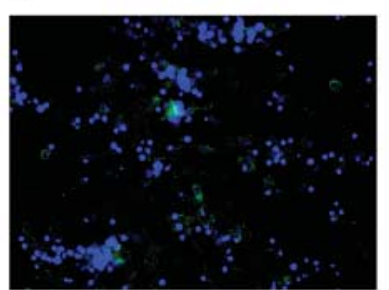

D

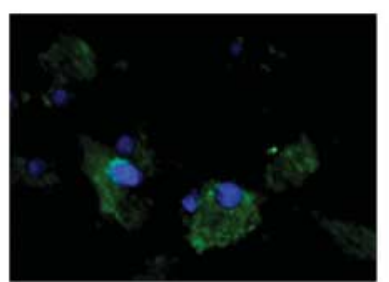

E

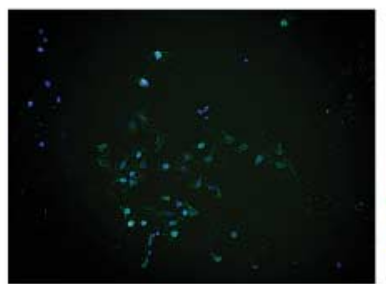

F

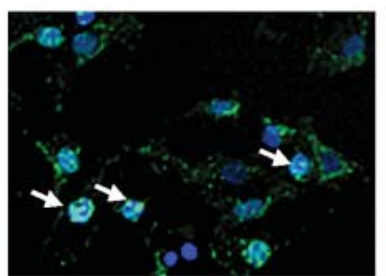

G

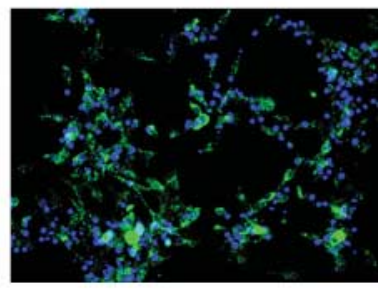

$\mathrm{H}$

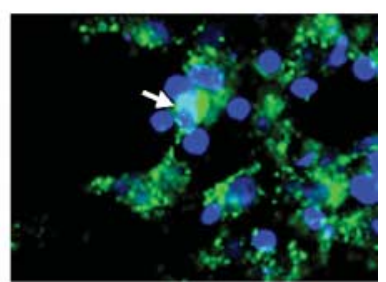

Figure 6 Phosphorylated Stat3 (p-Stat3) localization in granulosa cells in response to EGF stimulation. (a) p-Stat3 was minimum in granulosa cells in the absence of EGF; (c-h) p-Stat3 level was elevated in granulosa cells at 5 (C, D), 10 (E, F), and $15(\mathrm{G}, \mathrm{H})$ min of EGF stimulation. From 5 , 10 , and 15 min of EGF stimulation, p-Stat 3 was observed to be present in the nuclei of some granulosa cells ( $d$, $f$, $h$ arrow pointed). (b) Negative control in which primary antibodies were substituted with non-immune rabbit serum. Cells were counterstained with DAPI (blue) to show nuclei. Magnification: A, C, E, G: $200 \times ; B, D, F, H: 400 \times$.

granulosa, and theca cells within the ovary. The expression of Stat3 in theca cells has not been reported previously and future studies may investigate the role of Stat3 in this cell type. The role of Stat3 in the regulation of granulosa cell functions remains largely unclear, although it has been recently shown that Stat-3 mediates leptin's modulation of steroidogenesis in granulosa cells (Ruiz-Cortes et al. 2003). Interestingly, Stat3 is also involved in the regulation of oocyte maturation by leptin (Matsuoka et al. 1999). However, whether the Stat 3 pathway can be triggered by growth factors or cytokines in the ovary was unknown. This study demonstrated that EGF induced the phosphorylation of Stat3 in ovarian granulosa cells. Meanwhile the phosphorylated Stat3 translocated to the nuclei in response to EGF stimulation. These results suggest that EGF may be another activator of the Stat 3 pathway in granulosa cells. Interestingly, EGF is known to control the initial growth of granulosa cells (Driancourt \& Thuel 1998), apoptosis (Oliver et al. 1999), and the initiation of steroidogenesis (Li et al. 1995, Hernandez \& Bahr 2003). The regulation of granulosa cell function by EGF was previously shown to be mediated via the MAP kinases pathway (Keel et al. 1995, Keel \& Davis 1999). To our knowledge, this is the first report on the possible involvement of Stat3 in the EGF signaling in ovarian cells, irrespective of the animal species. Activation of the Stat3 pathway may be a novel mechanism of EGF action within the ovary.

\section{Acknowledgements}

This work was supported by Natural Sciences and Engineering Research Council (NSERC), Agriculture and Agri-Food Canada, and Premier's Research Excellence Awards to Julang Li. Jesse Craig and Paul W Dyce are recipients of NSERC scholarships. We also wish to thank the staff in the Meat Wing at the University of Guelph for their ongoing assistance. The authors declare that there is no conflict of interest that would prejudice the impartiality of this scientific work.

\section{References}

Aaronson DS \& Horvath CM 2002 A road map for those who know JAK-STAT. Science 296 1653-1655.

Akira S 1999 Functional roles of STAT family proteins: lessons from knockout mice. Stem Cells 17 138-146.

Akira S 2000 Roles of STAT3 defined by tissue-specific gene targeting. Oncogene 19 2607-2611.

Akira S, Nishio Y, Inoue M, Wang XJ, Wei S, Matsusaka T, Yoshida K, Sudo T, Naruto M \& Kishimoto T 1994 Molecular cloning of APRF, a novel IFN-stimulated gene factor 3 p91-related transcription factor involved in the gp130-mediated signaling pathway. Cell 77 63-71.

Calo V, Migliavacca M, Bazan V, Macaluso M, Buscemi M, Gebbia N \& Russo A 2003 STAT proteins: from normal control of cellular events to tumorigenesis. Journal of Celluar Physiology 197 157-168.

Chan KS, Carbajal S, Kiguchi K, Clifford J, Sano S \& DiGiovanni J 2004 Epidermal growth factor receptor-mediated activation of Stat3 during multistage skin carcinogenesis. Cancer Research 64 2382-2389.

Darnell JE Jr 1997 STATs and gene regulation. Science 277 1630-1635.

Driancourt MA \& Thuel B 1998 Control of oocyte growth and maturation by follicular cells and molecules present in follicular fluid. A review. Reproduction, Nutrition, Development 38 345-362.

Dyce PW, Zhu H, Craig J \& Li J 2004 Stem cells with multilineage potential derived from porcine skin. Biochemical and Biophysical Research Communications 316 651-658.

Greenlund AC, Morales MO, Viviano BL, Yan H, Krolewski J \& Schreiber RD 1995 Stat recruitment by tyrosine-phosphorylated cytokine receptors: an ordered reversible affinity-driven process. Immunity 2 677-687.

Guschin D, Rogers N, Briscoe J, Witthuhn B, Watling D, Horn F, Pellegrini S, Yasukawa K, Heinrich P, Stark GR, et al. 1995 A major 
role for the protein tyrosine kinase JAK1 in the JAK/STAT signal transduction pathway in response to interleukin-6. EMBO Journal 14 1421-1429.

Gutierrez CG, Ralph JH, Telfer EE, Wilmut I \& Webb R 2000 Growth and antrum formation of bovine preantral follicles in long-term culture in vitro. Biological Reproduction 62 1322-1328.

Hernandez AG \& Bahr JM 2003 Role of FSH and epidermal growth factor (EGF) in the initiation of steroidogenesis in granulosa cells associated with follicular selection in chicken ovaries. Reproduction 125 683-691.

Ihle JN 1995 The Janus protein tyrosine kinase family and its role in cytokine signaling. Advances Immunology 60 1-35.

Keel BA \& Davis JS 1999 Epidermal growth factor activates extracellular signal-regulated protein kinases (ERK) in freshly isolated porcine granulosa cells. Steroids 64 654-658.

Keel BA, Hildebrandt JM, May JV \& Davis JS 1995 Effects of epidermal growth factor on the tyrosine phosphorylation of mitogen-activated protein kinases in monolayer cultures of porcine granulosa cells. Endocrinology 136 1197-1204.

Li XM, Juorio AV \& Murphy BD 1995 Angiotensin II interferes with steroidogenesis in porcine granulosa cells. Biological Reproduction $53791-799$

Livak KJ \& Schmittgen TD 2001 Analysis of relative gene expression data using real-time quantitative PCR and the 2(-Delta Delta C(T)) Method. Methods 25 402-408.

Mao J, Smith MF, Rucker EB, Wu GM, McCauley TC, Cantley TC, Prather RS, Didion BA \& Day BN 2004 Effect of epidermal growth factor and insulin-like growth factor I on porcine preantral follicular growth, antrum formation, and stimulation of granulosal cell proliferation and suppression of apoptosis in vitro. Journal of Animal Science 82 1967-1975.

Matsuoka T, Tahara M, Yokoi T, Masumoto N, Takeda T, Yamaguchi M, Tasaka K, Kurachi H \& Murata Y 1999 Tyrosine phosphorylation of STAT3 by leptin through leptin receptor in mouse metaphase 2 stage oocyte. Biochemical and Biophysical Research Communications 256 480-484.

Oliver RH, Khan SM, Leung BS \& Yeh J 1999 Induction of apoptosis in luteinized granulosa cells by the MAP kinase kinase (MEK) inhibitor PD98059. Biochemical and Biophysical Research Communications 263 143-148.

Raz R, Durbin JE \& Levy DE 1994 Acute phase response factor and additional members of the interferon-stimulated gene factor 3 family integrate diverse signals from cytokines, interferons, and growth factors. Journal of Biological Chemistry 269 24391-24395.

Ripperger JA, Fritz S, Richter K, Hocke GM, Lottspeich F \& Fey GH 1995 Transcription factors Stat 3 and Stat $5 b$ are present in rat liver nuclei late in an acute phase response and bind interleukin- 6 response elements. Journal of Biological Chemistry 270 29998-30006.

Romano M, Kraus ER, Boland CR \& Coffey RJ 1994 Comparison between transforming growth factor alpha and epidermal growth factor in the protection of rat gastric mucosa against drug-induced injury. Italian Journal of Gastroenterology 26 223-228.
Ruiz-Cortes ZT, Martel-Kennes Y, Gevry NY, Downey BR, Palin MF \& Murphy BD 2003 Biphasic effects of leptin in porcine granulosa cells. Biological Reproduction 68 789-796.

Seidel HM, Milocco LH, Lamb P, Darnell JE Jr, Stein RB \& Rosen J 1995 Spacing of palindromic half sites as a determinant of selective STAT (signal transducers and activators of transcription) DNA binding and transcriptional activity. PNAS 92 3041-3045.

Shimoda K, Feng J, Murakami H, Nagata S, Watling D, Rogers NC, Stark GR, Kerr IM \& Ihle JN 1997 Jak1 plays an essential role for receptor phosphorylation and Stat activation in response to granulocyte colony-stimulating factor. Blood 90 597-604.

Shuai K 1999 The STAT family of proteins in cytokine signaling. Progress in Biophysics and Molecular Biology 71 405-422.

Stahl N, Farruggella TJ, Boulton TG, Zhong Z, Darnell JE Jr \& Yancopoulos GD 1995 Choice of STATs and other substrates specified by modular tyrosine-based motifs in cytokine receptors. Science 267 1349-1353.

Stewart CL, Kaspar P, Brunet LJ, Bhatt H, Gadi I, Kontgen F \& Abbondanzo SJ 1992 Blastocyst implantation depends on maternal expression of leukaemia inhibitory factor. Nature 359 76-79.

Takeda K, Noguchi K, Shi W, Tanaka T, Matsumoto M, Yoshida N, Kishimoto T \& Akira S 1997 Targeted disruption of the mouse Stat3 gene leads to early embryonic lethality. PNAS 94 3801-3804.

Teng CB, Diao HL, Ma H, Cong J, Yu H, Ma XH, Xu LB \& Yang ZM 2004a Signal transducer and activator of transcription 3 (Stat3) expression and activation in rat uterus during early pregnancy. Reproduction 128 197-205.

Teng CB, Diao HL, Ma XH, Xu LB \& Yang ZM 2004b Differential expression and activation of Stat3 during mouse embryo implantation and decidualization. Molecular Reproduction and Development 69 1-10.

Threadgill DW, Dlugosz AA, Hansen LA, Tennenbaum T, Lichti U, Yee D, LaMantia C, Mourton T, Herrup K, Harris RC et al. 1995 Targeted disruption of mouse EGF receptor: effect of genetic background on mutant phenotype. Science 269 230-234.

Yoshida H, Hayashi S, Kunisada T, Ogawa M, Nishikawa S, Okamura H, Sudo T \& Shultz LD 1990 The murine mutation osteopetrosis is in the coding region of the macrophage colony stimulating factor gene. Nature 345 442-444.

Zhong Z, Wen Z \& Darnell JE Jr 1994 Stat3: a STAT family member activated by tyrosine phosphorylation in response to epidermal growth factor and interleukin-6. Science 264 95-98.

Received 24 November 2005

First decision 19 January 2006

Revised manuscript received 3 April 2006

Accepted 22 June 2006 